\title{
Current practices in haemophilic patients undergoing orthopedic surgery - a systematic review
}

\author{
OANA VIOLA BADULESCU ${ }^{1 *}$, NINA FILIP ${ }^{2}$, PAUL DAN SIRBU $^{3 *}$, IRIS BARARU-BOJAN ${ }^{1}$, \\ MARIA VLADEANU ${ }^{1}$, ANDREI BOJAN ${ }^{4}$ and MANUELA CIOCOIU ${ }^{1}$
}

\author{
Departments of ${ }^{1}$ Pathophysiology, Morpho-Functional Sciences (II), ${ }^{2}$ Biochemistry, Morpho-Functional Sciences (II) \\ and ${ }^{3}$ Orthopedics and Traumatology Surgical Sciences (II), Faculty of Medicine; ${ }^{4}$ Department of Surgical Sciences, \\ 'Grigore T. Popa' University of Medicine and Pharmacy, 700115 Iasi, Romania
}

Received August 18, 2020; Accepted September 17, 2020

DOI: $10.3892 / \mathrm{etm} .2020 .9337$

\begin{abstract}
Haemophilia is an inherited disease that requires a different approach in order to evaluate, monitor and treat patients. Despite the great advances in therapeutic agents that have emerged, reports on the impact of monitoring outcomes on treatment decisions are rarely presented. Haemophilia A and haemophilia B are inherited bleeding disorders caused by deficiencies in blood clotting factor proteins. A systematic review was performed to identify literature reports on the current practices in haemophilic patients undergoing orthopedic surgery. The best therapy for haemophilic patients consists in performing primary prophylaxis to prevent joint bleeding and other complications. Besides the primary prophylaxis, thromboprophylaxis is used to prevent venous thrombosis in patients with hemophilia who undergo surgical orthopedic procedures. Further research is needed to better manage the pharmacologic approaches in haemophilic patients undergoing orthopedic surgery. Although patients with haemophilia present low risk for thromboembolic complications, such events have been reported in surgical procedures. The recommendations in patients with haemophilia are considerably variable in the current guidelines and clinical practice. The best therapy for haemophilic patients consists in performing primary prophylaxis to prevent joint bleeding and other complications.
\end{abstract}

Correspondence to: Dr Nina Filip, Department of Biochemistry, Morpho-Functional Sciences (II), Faculty of Medicine, 'Grigore T. Popa' University of Medicine and Pharmacy, 15 Otilia Cazimir Street, 700115 Iasi, Romania

E-mail: zamosteanu_nina@yahoo.com

Dr Iris Bararu-Bojan, Department of Pathophysiology, MorphoFunctional Sciences (II), Faculty of Medicine, 'Grigore T. Popa' University of Medicine and Pharmacy, 16 Universității Street, 700115 Iasi, Romania

E-mail: iris_bararu@yahoo.com

*Contributed equally

Key words: haemophilia, thromboprophylaxis, orthopedic surgery, arthropathy, haemophilia drugs

\section{Contents}

1. Introduction

2. Search strategy

3. Orthopaedic procedures in haemophilic patients

4. Pharmacologic thromboprophylaxis

5. Conclusions and prospects

\section{Introduction}

Haemophilia A, haemophilia B and von Willebrand disease (VWD) are inherited bleeding disorders of coagulation which represent $95 \%$ of all these diseases, while the remaining part is attributed to the rare bleeding disorders (RBDs) (1).

Haemophilia A, an X chromosome-linked disease is determined by deficiency of factor VIII and haemophilia B is due to a deficiency of factor IX. Clinical features of haemophilia $\mathrm{A}$ and $\mathrm{B}$ are almost identical, but the two haemophilic types can be separated on the basis of specific assays that distinguish between them (2).

The severity of hemophilia is classified according to the amount of the deficient coagulation factor present in the circulation. This is expressed as a percentage (100\% represent the normal concentration for the investigated coagulation factor): Mild disease results from a lower concentration between $5-40 \%$ of normal; moderate disease from $1-5 \%$ and those with severe disease have a concentration of less than $1 \%$ (3). Excessive bleeding is observed after minor trauma or surgery for patients with mild and moderate disease, whilst the patients with severe disease bleed spontaneously. The orthopedic problems of hemophilia have reduced since the introduction of prophylaxis using concentrates of the deficient coagulation factor (4).

Different treatment options are available for optimal management of bleeding and their prevention, and long-term outcomes are generally good. Initially the treatment for patients with hemophilia A consisted of administration of cryoprecipitates (enriched in factor VIII) prepared from individual donors or lyophilized factor VIII concentrates prepared from plasma pools of up to 5000 donors. It is now possible to prepare factor VIII by recombinant DNA technology. This 
Table I. Orthopaedic procedures in haemophilic patients.

\begin{tabular}{|c|c|c|c|}
\hline Orthopaedic procedures & Joint type & Key summary & (Refs.) \\
\hline \multirow[t]{3}{*}{ Arthroscopic synovectomy } & Elbows & $\begin{array}{l}\text { This procedure should be considered in young hemophilia } \\
\text { patients with chronic synovitis. }\end{array}$ & (8) \\
\hline & Knee & $\begin{array}{l}\text { An arthroscopic synovectomy of the knee using appropriate } \\
\text { arthroscopic portals is a useful method in treating haemophilic } \\
\text { patients as it decreases bleeding episodes, amount of factor } \\
\text { replacement and knee pain. }\end{array}$ & $(8,24,25)$ \\
\hline & Ankle & $\begin{array}{l}\text { Arthroscopic synovectomy significantly reduces joint pain, } \\
\text { prevents bleeding episodes, and improves joint function with } \\
\text { few complications. }\end{array}$ & $(8,26)$ \\
\hline \multirow[t]{2}{*}{ Osteotomy } & Knee & $\begin{array}{l}\text { The patient can benefit from this treatment option so that joint, } \\
\text { replacement may possibly be avoided or at least postponed to } \\
\text { a later stage of life. }\end{array}$ & $(27-29)$ \\
\hline & Hip & $\begin{array}{l}\text { Intertrochanteric varus osteotomy for haemophilic arthropathy } \\
\text { of the hip is an alternative to joint arthroplasty. }\end{array}$ & (29) \\
\hline Arthrodesis (joint fusion) & Ankle & $\begin{array}{l}\text { Arthrodesis in young patients with haemophilia resulted in } \\
\text { good long-term functional outcome, with a low surgery-related } \\
\text { complication rate. }\end{array}$ & $(9,11,30,31)$ \\
\hline \multirow[t]{3}{*}{ Arthroplasty } & Knee & $\begin{array}{l}\text { Total knee replacement is considered the gold standard for the } \\
\text { treatment of end stage chronic arthropathy in hemophilic } \\
\text { patients. }\end{array}$ & $(16,32)$ \\
\hline & Hip & $\begin{array}{l}\text { Total hip replacement in haemophilic patients leads to a } \\
\text { significant increase of function, reduction of pain and a high } \\
\text { satisfaction. }\end{array}$ & $(33,34)$ \\
\hline & Ankle & $\begin{array}{l}\text { Ankle arthroplasty in hemophilic patients leads to pain relief } \\
\text { and improves joint mobility in the vast majority of patients. }\end{array}$ & $(35-37)$ \\
\hline
\end{tabular}

type of preparations is free of contaminating viruses (e.g., hepatitis A, B, C, or HIV-1) found in human plasma.

The management of patients with haemophilia is complex as their condition is associated with a large number of comorbidities. Joint problems resulting from recurrent haemarthrosis, such as chronic synovitis and degenerative arthritis represent an important cause of morbidity (5).

\section{Search strategy}

We used Science Direct, Scopus, PubMed, Google Scholar to search original articles and review articles published in English language with the following key words 'haemophilia', 'orthopaedic surgery' and 'arthropathy'. The scientific databases were searched from January 2000 to January 2019. Only full-text, English-language papers were selected. Duplicate publications, irrelevant topics and book chapters were excluded.

\section{Orthopaedic procedures in haemophilic patients}

Orthopaedic surgery is a viable option to manage a target joint for haemophilic patients with severe arthropathy associated with persistent symptoms $(6,7)$. Surgical orthopaedic procedures generally used for the haemophilic patients are presented in Table I.

Regarding arthroscopic synovectomy of the knee, ankle and elbow, Journeycake et al (8) reported that the frequency of hemarthrosis diminished significantly in the first year after orthopaedic procedures. They concluded that arthroscopic synovectomy should be considered in young hemophilia patients with chronic synovitis.

In 2005, Panotopoulos et al (9) reported no early postoperative complications after three arthrodeses of the subtalar joint and one triple arthrodesis performed with screws and staples. Screw removal was required because of mechanical irritation of soft tissues in two cases after 4 and 12 months, respectively. For advanced haemophilic arthropathy of the ankle, the best solution is an ankle arthrodesis $(10,11)$.

\section{Pharmacologic thromboprophylaxis}

The major complication that may occur in the patient with haemophilia undergoing total arthroplasty is postoperative bleeding. Considering major bleeding risk of a haemophilia patient, mainly by coagulopathy but also due to surgery, most of the endoprostheses are aimed to provide the required amount of coagulation factor for the substitution treatment. Currently, standard patient care protocols sustain the need for using a haemostatic product, so once administered it could achieve effective haemostasis. In this regard, the use of Moroctocog alfa (a 3rd generation recombinant coagulation factor VIII) in patients with type A haemophilia has proven its safety and effectiveness in orthopaedic surgery $(12,13)$. For of haemophilia patients with inhibitors undergoing total knee 
Table II. Thromboprophylactic agents and their mechanism of action.

\begin{tabular}{ll}
\hline Drug & \multicolumn{1}{c}{ Mechanism of action } \\
\hline $\begin{array}{l}\text { Aspirin } \\
\text { Rivaroxaban }\end{array}$ & $\begin{array}{l}\text { Irreversibly blocks cyclooxygenase and the formation of thromboxane A2 } \\
\text { (platelet aggregator). } \\
\text { Inhibits directy factor Xa. } \\
\text { Inhibits the vitamin K epoxide reductase complex 1 (VKORC1) ( an essential } \\
\text { enzyme for activating the vitamin K available in the body). } \\
\text { Inhibits coagulation by activating antithrombin III. Antithrombin III binds to } \\
\text { and inhibits factor Xa. }\end{array}$ \\
$\begin{array}{l}\text { Low-molecular-weight heparin (LMWHs) } \\
\text { Nemiparin }\end{array}$ & $\begin{array}{l}\text { Reviparin } \\
\text { Enoxaparin }\end{array}$ \\
$\begin{array}{l}\text { Dalteparin } \\
\text { Tinzaparin } \\
\text { Fondaparinux }\end{array}$ & \\
\hline
\end{tabular}

replacement surgery, tranexamic acid used as anti-fibrinolytic agent, has been proven to be efficient in reducing hemorrhagipareous phenomena (14).

Holme and Tjønnfjord (15) reported the efficacy of Simoctocog alfa (a 4 th generation recombinant FVIII produced in a human cell line without chemical modification or fusion with any other protein) delivered by continuous infusion for bleeding prophylaxis during arthroplasty in patients with haemophilia A.

Silva and Luck Jr (16) reported the risk of infection for total knee replacement is about $16 \%$, and that risk can increase for the ankle because of the poor soft tissue envelope. In the non-haemophilic population, the rate of failure is high, as a result of infection and loosening, similarly to that seen in persons with haemophilia.

The use of thromboprophylaxis is recommended for non-haemophilic patients undergoing orthopedic surgeries because of the particularly well recognized high risk for venous thromboembolism. The drugs prescribed to prevent thrombus formation in total joint arthroplasty are presented in Table II $(17,18)$.

Although patients with haemophilia present low risk for thromboembolic complications, such events have been reported in surgical procedures. Orthopedic surgeries are often required in patients with haemophilia, due to the presence of haemophiliac arthropathy. Arthropathy mainly involves synovial joints, such as elbows, ankles and knees.

Rodríguez-Merchán and De la Corte-García (19) suggested the same type of pharmacological thromboprophylaxis for haemophilic patients undergoing orthopedic surgery as for non-haemophilic patients, if the haemophilic ones present several risk factors for thromboembolism. For hemophilia patients treated with inhibitor, pharmacologic thromboprophylaxis is not recommended (20).

Dargaud et al (21) reported that haemophilic patients should not routinely receive thromboprophylaxis, but specific cases with increased risk of thrombosis should receive therapy with LMWH.
Krekeler et al (22) analysed 105 interventions on haemophilic patients, 90 of them being major orthopaedic surgeries and 15 minor surgeries. The authors did not find any case of deep vein thrombosis or lung embolism when therapy with LWMH was not given after surgery. For haemophilia patients the use of venous thrombosis prophylaxis during orthopedic surgeries remains controversial (23).

The presence of particular surgical indications, the need for different surgical techniques and dedicated multidisciplinary post-operative care and the higher rate of complication have to be clearly highlighted.

\section{Conclusions and prospects}

In summary, the recommendations in patients with haemophilia are considerably variable in the current guidelines and clinical practice. The best therapy for haemophilic patients consists in performing primary prophylaxis to prevent joint bleeding and other complications. Patients with hemophilia should be clearly informed on the risk-benefit ratio of each surgical procedure taking into account functional outcome, quality of life improvement and the risk of complications. Further research is needed in order the settle general current guidelines and clinical practices, to achieve better management of haemophilic patients undergoing orthopedic surgery.

\section{Acknowledgements}

Not applicable.

\section{Funding}

No funding was received.

\section{Availability of data and materials}

The datasets used and/or analyzed during the current study are available from the corresponding author on reasonable request. 


\section{Authors' contributions}

OVB and PDS analyzed and interpreted the patient data regarding the hematological and orthopaedic disease. NF and IBB performed literature research and wrote the first draft of the manuscript. MV and AB collected data and participated in discussion. MC designed the study and supervised the whole process. All authors read and approved the final manuscript.

\section{Ethics approval and consent to participate}

Not applicable.

\section{Patient consent for publication}

Not applicable.

\section{Competing interests}

The authors declare that they have no competing interests.

\section{References}

1. Peyvandi F, Palla R, Menegatti $\mathrm{M}$ and Mannucci PM: Introduction: Rare bleeding disorders: General aspects of clinical features, diagnosis and management. Semin Thromb Hemost 35 : 349-355, 2009.

2. Murray RK, Granner DK, Mayes PA and Rodwell VW: Harper's Biochemistry. 25th Edition, McGraw-Hill, Health Profession Division, New York, 225, 2000.

3. World Federation of Hemophilia. WFH guidelines for the management of hemophilia. Available at: https://www1.wfh. org/publication/files/pdf-1472.pdf.

4. Rodriguez-Merchan EC: Prevention of the musculoskeletal complications of hemophilia. Adv Prev Med 2012: 201271, 2012

5. Knobe K and Berntorp E: Haemophilia and joint disease: Pathophysiology, evaluation, and management. J Comorb 1: $51-59,2011$.

6. Rizzo AR, Zago M, Carulli C and Innocenti M: Orthopaedic procedures in haemophilia. Clin Cases Miner Bone Metab 14 197-199, 2017.

7. Rodríguez-Merchán EC: The role of orthopaedic surgery in haemophilia: Current rationale, indications and results. EFORT Open Rev 4: 165-173, 2019.

8. Journeycake JM, Miller KL, Anderson AM, Buchanan GR and Finnegan M: Arthroscopic synovectomy in children and adolescents with hemophilia. J Pediatr Hematol Oncol 25: 726-731, 2003.

9. Panotopoulos J, Hanslik-Schnabel B, Wanivenhaus A and Trieb K: Outcome of surgical concepts in haemophilic arthropathy of the hindfoot. Haemophilia 11: 468-471, 2005.

10. Luck JV Jr, Silva M, Rodriguez-Merchan CE, Ghalambor N, Zahiri CA and Finn RS: Hemophilic arthropathy. J Am Acad Orthop Surg 12: 234-245, 2004.

11. Rodriguez-Merchan EC: The haemophilic ankle. Haemophilia 12: 337-344, 2006

12. Badulescu OV, Ciocoiu M, Filip N and Veringa V: The efficiency of substitutive treatment with moroctocog alfa in managing hemostasis in patients with hemophilia A without inhibitors with total knee arthroplasties. Rev Chim-Bucharest 69: 3702-3704, 2018.

13. d'Oiron R, Pipe SW and Jacquemin M: Mild/moderate haemophilia A: New insights into molecular mechanisms and inhibitor development. Haemophilia 14 (Suppl 3): S138-S146, 2008.

14. Badulescu OV, Ciocoiu M, Filip N and Veringa V: Tranexamic acid-major antifibrinolytic agent used to achieve hemostasis in hemophilic patients with anti-factor VIII antibodies who must undergo total joint replacement. Rev Chim-Bucharest 70: 638-641, 2019

15. Holme PA and Tjønnfjord GE: Continuous infusion of simoctocog Alfa in haemophilia A patients undergoing surgeries. Haemophilia 25: 54-59, 2009.
16. Silva M and Luck JV Jr: Long-term results of primary total knee replacement in patients with hemophilia. J Bone Joint Surg Am 87: 85-91, 2005.

17. Knesek D, Peterson TC and Markel DC: Thromboembolic prophylaxis in total joint arthroplasty. Thrombosis 2012: 837896, 2012.

18. Gali JC and Camargo DB: Thromboprophylaxis for total knee arthroplasty. Rev Bras Ortop (Sao Paulo) 54: 1-5, 2019.

19. Rodríguez-Merchán EC and De la Corte-García H: Orthopedic surgery in hemophilia: Is thromboprophylaxis necessary? Joint surgery in the adult patient with hemophilia. Springer, Cham, pp83-87, 2015.

20. Ozelo MC: Surgery in patients with hemophilia: Is thromboprophylaxis mandatory? Thromb Res 130 (Suppl 1): S23-S26, 2012.

21. Dargaud Y, Meunier S and Negrier C: Haemophilia and thrombophilia: An unexpected association! Haemophilia 10: 319-326, 2004.

22. Krekeler S, Alesci S and Miesbach W: Incidence of thromboembolic events after major operations in patients with haemophilia. Hamostaseologie 32 (Suppl 1): S45-S47, 2012 (In German).

23. Hosseini F, Squire SJ, Younger AS and Jackson SC: A 13-year review of elective orthopaedic surgery outcomes in patients with hemophilia A and B. BC Med J 61: 250-255, 2019.

24. Rampal V, Odent T, Torchet MF, Rothschild C, Elie C, Glorion C and Padovani JP: Surgical synovectomy of the knee in young haemophiliacs: Long-term results of a monocentric series of 23 patients. J Child Orthop 4: 33-37, 2010.

25. Yoon KH, Bae DK, Kim HS and Song SJ: Arthroscopic synovectomy in haemophilic arthropathy of the knee. Int Orthop 29: 296-300, 2005

26. Wu LT, Lu HT, Chen CH, Ko A and Lee CH: Arthroscopic synovectomy considerably reduces bleeding frequency and improves joint function in hemophilic patients with chronic synovitis. Formos J Surg 49: 49-55, 2016.

27. Caviglia H, Eljatib A, Del Soldato G, Daffunchio C, Landro ME and Neme D: Complications of ankle arthroscopy synovectomy. In: Haemophilia. Wiley, NJ, p82, 2018.

28. Trieb K, Panotopoulos J, Hartl H, Brodner W, Pabinger I and Wanivenhaus A: Outcome of osteotomies for the treatment of haemophilic arthropathy of the knee. Langenbeck Arch Surg 389: 209-212, 2004.

29. Wallny T, Saker A, Hofmann P, Brackmann HH, Nicolay C and Kraft CN: Long-term follow-up after osteotomy for haemophilic arthropathy of the knee. Haemophilia 9: 69-75, 2003.

30. De l'Escalopier N, Badina A, Padovani JP, Harroche A, Frenzel L, Wicart P, Glorion C and Rothschild C: Long-term results of ankle arthrodesis in children and adolescents with haemophilia. Int Orthop 41: 1579-1584, 2017.

31. Fong JY, Luck JV and Silva M: Ankle fusion in hemophilia. In: Annual Meeting. San Diego, CA: American Academy of Orthopaedic Surgery, 2007.

32. Moore MF, Tobase P and Allen DD: Meta-analysis: Outcomes of total knee arthroplasty in the haemophilia population. Haemophilia 22: e275-e285, 2016.

33. Carulli C, Felici I, Martini C, Civinini R, Linari S, Castaman G and Innocenti M: Total hip arthroplasty in haemophilic patients with modern cementless implants. J Arthroplasty 30: 1757-1760, 2015.

34. Strauss AC, Rommelspacher Y, Nouri B, Bornemann R, Wimmer MD, Oldenburg J, Pennekamp PH and Schmolders J: Long-term outcome of total hip arthroplasty in patients with haemophilia. Haemophilia 23: 129-134, 2017.

35. Doets HC, Brand R and Nelissen RG: Total ankle arthroplasty in inflammatory joint disease with use of two mobile-bearing designs. J Bone Joint Surg Am 88: 1272-1284, 2006.

36. Radossi P, Bisson R, Munari F, Risato R, Tassinari C, Sartori R and Tagariello G: Total ankle replacement for end-stage arthropathy in patients with haemophilia. Haemophilia 14: 658-660, 2008.

37. Van Der Heide HJ, Nováková I and de Waal Malefijt MC: The feasibility of total ankle prosthesis for severe arthropathy in haemophilia and prothrombin deficiency. Haemophilia 12: 679-682, 2006. 